\title{
INTERÉS MÁXIMO CONVENCIONAL EN LOS CONTRATOS DE LEASING Y OTRAS FIGURAS AFINES: COMENTARIO A LA SENTENCIA DEL TRIBUNAL ARBITRAL DE SEGUNDA INSTANCIA COMPUESTO POR LOS ÁRBITROS ENRIQUE BARROS BOURI, MIGUEL LUIS AMUNÁTEGUI MÖNCKEBERG Y ANTONIO BASCUÑÁN VALDÉS, EN LA CAUSA DE AUTOS CARATULADOS: INMOBILIARIA S.W. DEPORTES S.A. CON PENTA VIDA COMPAÑÍA DE SEGUROS DE VIDA S.A.*
}

\author{
MAXIMUM INTEREST RATE IN LEASING AGREEMENTS AND \\ CONTRACTS AND OTHER RELATED FIGURES: COMMENTS TO THE \\ SECOND INSTANCE DECISION ISSUED BY THE ARBITRAL COURT \\ FORMED BYTHE ARBITRATORS ENRIQUE BARROS BOURIE, MIGUEL \\ LUIS AMUNATEGUI MONKEBERG AND ANTONIO BASCUNAN VALDES \\ IN THE LEGAL CASE (ENTITLED) INMOBILIARIA S.W. DEPORTES S.A. \\ CON PENTA VIDA COMPANIIAA DE SEGUROS DE VIDA S.A.
}

\section{Rodrigo Pablo P.}

\begin{abstract}
RESUMEN: el presente trabajo analiza la sentencia de fecha 12 de noviembre del año 2014, a la que hace referencia el título; la que se hace cargo de concepto de operación de crédito de dinero y lo aplica a la figura del leasing. Dando criterios para reconocer cuando nos encontramos ante una operación de crédito de dinero a la que sea, por tanto, aplicable la regulación de los intereses y de la usura que establece la Ley No 18.010.
\end{abstract}

Palabras clave: Operación de crédito de dinero, intereses, usura, leasing.

ABSTRACT: This paper analyses the judicial decision of November 12, 2014 referred to in the title, which covers credit transactions and applies them to leasing. Providing criteria to recognize the credit transactions to which the regulation of interests and usury set forth in Law 18,010 is applicable.

Key words: Credit transactions, interests, usury, leasing.

\footnotetext{
El presente comentario no se hace cargo de toda la sentencia, sino solo de lo concerniente a si el leasing queda comprendido dentro del concepto de operación de crédito de dinero.

** Abogado, licenciado en derecho por la Pontificia Universidad Católica de Chile. Dirección postal: Alcántara 154, Las Condes, Santiago. Dirección electrónica: rjpablo@uc.cl.
} 


\section{INTRODUCCIÓN}

De un tiempo a esta parte se ha desarrollado en nuestro país un importante problema de interpretación legal, acerca del alcance de la regulación establecida por la Ley No 18.010, que establece normas para las operaciones de crédito y otras obligaciones de dinero que indica (en adelante la Ley No 18.010). Este consiste en la definición y alcance que se le da a los conceptos de operación de crédito de dinero, contenido en el artículo $1^{\circ 1}$; y de interés, contenido en el artículo $2^{\circ 2}$, ambos de la Ley № 18.010 .

La sentencia objeto de este comentario viene a hacerse cargo de este problema dando luces para la correcta interpretación de la ley, y, si bien, ella se da en el contexto de un contrato de leasing, las conclusiones que de ella se extraen son útiles para determinar la aplicación de la Ley No 18.010 en cualquier tipo de actos jurídicos.

En lo sucesivo se introducirá al lector al problema de los intereses; se le explicará el caso sometido a la decisión del tribunal y la decisión de este; se darán los argumentos que tiene este comentarista para sostener su postura al respecto; y, finalmente, se extenderán las conclusiones a otras figuras afines a la que fue objeto de la resolución de los árbitros.

\section{LOS INTERESES}

$\mathrm{Al}$ respecto de esta materia, demos primero las definiciones de interés que se han dado por distintos autores desde diversos puntos de vista: a) "el lucro producido por el capital; rendimiento o incremento pecuniario del capital; corresponde al precio que tiene el dinero en el mercado financiero en un momento determinado"3; b) "el precio que se paga por conseguir dinero prestado. Por lo general, el interés se calcula como un porcentaje anual sobre la cantidad de fondos prestados. Hay múltiples tasas de interés que dependen del vencimiento, del riesgo, del tratamiento fiscal y de otros atributos" ", y c) "lucro producido por el capital”.

Dadas las definiciones, digamos que con la regulación de los intereses, tradicionalmente, se ha buscado evitar la usura; de la que ha dicho un autor: "la totalidad de la doctrina contemporánea, tanto los autores católicos, como los naturalistas, como los positivistas, están de acuerdo en absoluto con la inmoralidad de la usura y buscan y claman por la aplicación de medios legales de represión" ${ }^{\text {. }}$

\footnotetext{
1 Artículo $1^{\circ}$ de la Ley No 18.010 de 1981: "aquellas por las cuales una de las partes entrega o se obliga a entregar una cantidad de dinero y la otra a pagarla en un momento distinto de aquel en que se celebra la convención.

2 Artículo $2^{\circ}$ de la Ley No 18.010 de 1981: En las operaciones de crédito de dinero no reajustables, constituye interés toda suma que recibe o tiene derecho a recibir el acreedor, a cualquier título, por sobre el capital. Se entiende por tasa de interés de una operación de crédito de dinero no reajustable, la relación entre el interés calculado en la forma definida en este inciso y el capital. En las operaciones de crédito de dinero reajustables, constituye interés toda suma que recibe o tiene derecho a recibir el acreedor por sobre el capital reajustado. Se entiende por tasa de interés de un crédito reajustable, la relación entre el interés calculado en la forma definida en este inciso y el capital. En ningún caso, constituyen intereses las costas personales ni las procesales.

3 Labbe (2010) p. 197

4 Samuelson y Nodhaus (2010) p. 468.

5 Diccionario de la Real Academia de la Lengua Española.

${ }^{6}$ Vizcarro (1963) p. 6 Hoy quizás, por las teorías económicas imperantes esta afirmación no sería igualmente válida.
} 
Aristóteles, Santo Tomás y la mayoría de los teólogos y juristas clásicos desconocieron el derecho a cobrar interés en los préstamos. Argumentaban que en el mutuo el mutuario se hace dueño de la cosa prestada, de modo que de perecer esta, perece para él, siguiendo por ende obligado a restituirla. Por lo anterior, el mutuante no corre riesgo alguno para sí. Además, por el hecho de hacerse el mutuario dueño de la cosa prestada, no se puede hablar de una renta por el dinero ${ }^{7}$.

Así, Tomás de Aquino señala: "Recibir interés por el dinero prestado es injusto, porque se vende lo que no existe, por lo cual manifiestamente se constituye una desigualdad que contraría a la justicia"... "El que presta en mutuo transfiere el dominio del dinero a aquel a quien presta. De donde es que aquel, al cual se presta el dinero, lo tiene a su propio riesgo y está obligado a restituirlo íntegramente. Por lo cual no debe exigir más aquel que prestó. Mas aquel que encomendó su dinero a un comerciante o artesano, en una especie de sociedad, no le transfiere el dominio de su dinero, sino que sigue siendo suyo, de modo que a riesgo del mismo negocia con él el comerciante o el artesano trabaja. Y por tanto aquel puede pedir parte de la ganancia proveniente de allí como cosa propia"8.

Posteriormente los seguidores de esta escuela aceptaron el derecho a cobrar interés; ya sea para cubrir el daño emergente que por el hecho del mutuo pueda sufrir el mutuario, el lucro cesante que se le pueda producir por el mismo hecho o los riesgos de la solvencia del deudor. De este modo se consideró, por estos pensadores, que en el interés es una indemnización.

Siguiendo adelante con esta evolución doctrinaria, en el Siglo XX los autores que siguen esta escuela señalan que en la realidad económica actual el dinero es un bien siempre productivo y que en el préstamo comercial (que no era tenido a la vista por Santo Tomás y Aristóteles) lo que hay es un verdadero arriendo de capital. En Chile, Fernández Concha desarrolló la tesis del contrato trino, la que entiende que en el mutuo con fines comerciales hay tres contratos: a) el de sociedad, por el cual el capitalista pone el dinero y el comerciante el trabajo; b) el de seguro, por el cual el comerciante asegura al capitalista una determinada utilidad, y c) el de venta, por el cual el capitalista vende al comerciante la expectativa de ganancia en un precio que es un porcentaje del capital: el interés 9 .

De este modo se aceptó por la doctrina más influyente, de nuestra trayectoria histórica, el interés, manteniendo, sin embargo, el ordenamiento jurídico la intención de regularlo.

Dicha regulación podemos encontrarla en nuestro derecho positivo en distintos cuerpos normativos. En primer lugar, mencionemos la Convención Americana de Derechos Humanos, denominada "Pacto San José de Costa Rica", que estatuye en su artículo 21 No 3, a propósito de la consagración del derecho de propiedad: "tanto la usura como cual-

\footnotetext{
7 UGARTe (2010) p. 658. A este respecto, es conveniente, además, señalar lo dicho por Aristóteles: "el préstamo con interés es odiado con plenitud de razones, a causa de derivar su provecho del dinero mismo y no de aquello para lo que este se introdujo. El dinero, en efecto, hizose por causa de cambio, pero en el préstamo que decimos el interés multiplica el dinero" (De Estagiria, Aristóteles (2013): “La Política” (Traducción de Antonio López, Ciudad de México, Editorial Porrúa). 223-224 pp.).

8 Suma Teológica 2-2, q.78, a.1, c y a.2, ad.5, citado por UGarte (2010) pp. 658-659.

9 Ugarte (2010) 659-660 pp.
} 
quier otra forma de explotación del hombre por el hombre debe ser prohibida por la ley"10. En segundo lugar, digamos que en el derecho interno, la regulación del monto de intereses que es permitido estipular, y la regulación de los mismos, se encuentra desparramada en distintos cuerpos legales, siendo los principales el artículo 2.206 del Código Civil; las disposiciones de la Ley No 18.010, y el artículo 472 del Código Penal, que establece el delito de usura.

En otro orden de cosas, debemos hacer presente, que las escuelas económicas más liberales han aceptado desde su aparición a fines del siglo XVIII la libertad en el pacto de intereses. Han sostenido que el dinero es un bien que, como cualquier otro, puede ser objeto de toda clase de contratos. No obstante ello, no nos detendremos en este punto por no haber predominado esta doctrina - de la total libertad del pacto de intereses- en Chile, y por no ser el objeto de este trabajo hacer un recorrido exhaustivo de la justicia de los intereses.

\section{HECHOS}

El contrato de arriendo con promesa de compraventa (el "leasing") que dio origen al juicio, tuvo sus antecedentes en el contrato de compraventa, arriendo y promesa de compraventa (que las partes convinieron en llamar leas-back durante el juicio) celebrado por escritura pública de fecha 13 de octubre de 2005 en la Notaría de Santiago de Antonieta Mendoza Escala, entre Holding One Limitada (en adelante "Holding One") y Penta Vida Compañía de Seguros de Vida S.A. (en adelante "Penta").

En virtud de dicho contrato, Holding One vendió a Penta tres inmuebles de su propiedad en la suma de 180.000 UF, obligándose Penta, además de a las obligaciones esenciales y de la naturaleza que emanan del contrato de compraventa, a dar en arrendamiento los inmuebles a Holding One por un plazo de 20 años, y obligándose esta última sociedad a pagar una mensualidad compuesta por la renta de arrendamiento más una cuota de un fondo de compra y el impuesto territorial que corresponde a los inmuebles (en adelante a esta operación la denominaremos el "Contrato Primitivo").

Producto de dificultades tenidas por Holding One para dar cumplimiento a sus obligaciones, Penta accedió a una reorganización del negocio; que consistió en que por escritura pública de fecha 17 de junio de 2008, otorgada en la Notaría de Santiago de Patricio Raby Benavente, Penta y Holding One pusieron término al arrendamiento; resciliaron la promesa de compraventa; y Penta firmó un nuevo contrato de arrendamiento con promesa de compraventa en las mismas condiciones que el anterior, pero reconociendo 29 meses de cuotas pagadas, con Comercial G y D Sports Limitada -hoy Inmobiliaria S.W. Deportes S.A. (en adelante "S.W.")-, compañía en la que participaban los mismos socios de Holding One Limitada (en adelante el "Contrato"). En dicho contrato, S.W. se obligó a pagar 211 cuotas mensuales, hasta enterar el valor de 169.602,434 UF.

\footnotetext{
10 Artículo 21 No 3, Convención Americana de Derechos Humanos. Este tratado fue suscrita por Chile el 22 de noviembre de 1969, aprobado por el Congreso Nacional el 14 de agosto de 1990, ratificado con fecha 21 de agosto de 1990 y publicado en el Diario Oficial el 5 de enero de 1991.
} 
Con posterioridad, el 28 de marzo de 2012, S.W. interpuso demanda de reducción de intereses y devolución de los pagados excesivamente en contra de Penta ${ }^{11}$, ante el tribunal arbitral designado en el Contrato.

El demandante adujo que lo que el Contrato denomina renta, son, en realidad, intereses que excederían la tasa máxima convencional que está permitido estipular en operaciones de préstamo que exceden de 2.000 UF. Señaló que, de considerar la renta como interés, la tasa sería de un $0,58 \%$ mensual y 7,15\% anual, lo que al agregar el monto de las contribuciones aumentaría a 0,626\% mensual y 7,74\% anual; valores que están por sobre la tasa máxima convencional a la época de celebración del Contrato, que era de 0,515\% mensual o $6,36 \%$ anual.

En apoyo de su tesis indica: que la renta se reduce después del mes 115, al igual que tasa de interés en los créditos; que el contrato hace recaer el riesgo de cualquier problema que sufra el inmueble sobre S.W.; que se requiere autorización de Penta para poder subarrendar los inmuebles; que en el Contrato Penta declara que adquirió el inmueble solo para darlo en arrendamiento a S.W.

Así llega a concluir que nos encontramos ante una operación dineraria que queda sujeta a lo establecido en la Ley No 18.010 y en el artículo 2.206 del Código Civil.

Por su parte, Penta niega la tesis de S.W., y sostiene que en el caso de marras no se cobran intereses y que el leasing, en sus distintas modalidades, no puede ser considerado como una operación de crédito de dinero de las reguladas por la Ley No 18.010 y el artículo 2.206 del Código Civil.

Penta señala que las cuotas corresponden a rentas de arrendamiento libremente pactadas por el uso y goce de los inmuebles; más una mensualidad por el fondo de compra que constituye el precio por el que el arrendatario y promitente comprador recobraría el dominio de los inmuebles. Indica, que la renta efectivamente lleva implícita "una tasa”, mas no de interés por un crédito, sino una que representa la rentabilidad que Penta espera del negocio inmobiliario del que está participando. Sobre la amortización añade que ella no se refiere al capital prestado, sino al invertido en el negocio inmobiliario.

Agrega sobre el derecho y la clasificación del contrato; que el leasing no es una simulación, sino un contrato atípico integrado por dos contratos típicos: el arrendamiento y la promesa de compraventa; los que son usados de manera integrada con un fin distinto del que típicamente se les da, este es: otorgar financiamiento. Añade que esta finalidad no lo convierte en una operación de crédito de dinero.

En apoyo de este punto expone que la Superintendencia de Bancos e Instituciones Financieras (en adelante la "SBIF") no considera las rentas de arrendamiento de una operación de leasing para determinar la tasa máxima convencional, y que en el Contrato Primitivo no se da ninguna de las características que de acuerdo con la Ley No 18.010 nos ponen en presencia de una operación de crédito de dinero, ya que Penta no entregó

\footnotetext{
11 La demanda es más amplia, incluye la derogación de una cláusula por considerársele abusiva, pero en este trabajo, como se dice al comenzar, nos limitamos solo al punto referente a la comprensión del leasing dentro del concepto de operación de crédito de dinero y a la regulación de los intereses.
} 
ni se obligó a entregar una cantidad de dinero generando en Holding One, ahora S.W., la obligación de restituir.

Termina su argumentación señalando que en esta operación no se ha pagado el impuesto de timbres y estampillas, tributo que sí grava las operaciones de crédito de dinero.

\section{ANTECEDENTES PRELIMINARES: FALLO DE PRIMERA INSTANCIA DICTADO POR EL JUEZ ÁRBITRO RAÚL TAVOLARI OLIVEROS}

El juez árbitro de primera instancia, centro su análisis del caso en determinar cuál era la naturaleza jurídica del contrato celebrado. Para, de acuerdo con dicha naturaleza, determinar si se trata de una operación de crédito de dinero.

Con este objeto en mente decidió analizar el motivo del Contrato, al cual dio el alcance de causa del mismo ${ }^{12}$, buscando develar qué fue lo que las partes realmente quisieron convenir. De esta manera, el árbitro arribó a la conclusión de que lo verdaderamente querido por las partes era celebrar un financiamiento que consistía en distintas operaciones por medio de las cuales una parte entrega dinero a otra, obligándose la segunda a restituirlo en un tiempo distinto; es decir una operación de crédito de dinero.

Para sostener esta conclusión, el señor Tavolari se apoya en la Historia de la Ley No 18.010; doctrina nacional y extranjera, y jurisprudencia de nuestros tribunales superiores de justicia ${ }^{13}$.

Con respecto a la historia de la ley, señala el árbitro que en el artículo $1^{\circ}$ del proyecto de ley que daría origen a la Ley No 18.010, se definía a las operaciones de crédito de dinero como: "aquellas por las cuales una de las partes se obliga a entregar, a la otra, una cantidad determinada de dinero; y la otra a pagarla, en un momento distinto de aquel en que se celebre la convención" ${ }^{14}$. Agregando el informe técnico del proyecto que: "El proyecto aclara que en todo caso, es operación de crédito de dinero toda combinación de negocios o de determinadas modalidades dentro de un contrato, que en la práctica conduzca al resultado previsto en la definición de operación de crédito de dinero, como por ejemplo, el pacto de retroventa, las compras y ventas cruzadas y otras convenciones semejantes" 15 .

El juez concluye su análisis de la Historia de la Ley citando el informe de la Secretaría de Legislación que quiso imponer una limitación al concepto de operaciones de crédito de dinero y a la regulación de la -en ese entonces- futura ley señalando: "Para efectos de restringir algunas normas de la legislación solo a aquellas operaciones que son propiamente de crédito, lo artículos distinguen entre 'operaciones de crédito de dinero' y 'obligaciones de dinero', siendo para los efectos de esta normativa, el género las obligaciones de dinero; y las de crédito en dinero, una especie de estas. Lo anterior se desprende de la circunstancia de que la legislación es en general aplicable a toda obligación en que una de las partes se

\footnotetext{
12 En esto Tavolari acogió la teoría minoritaria, tanto en Chile como en el derecho comparado, que busca la causa del acto jurídico en el motivo que tuvieron las partes para contratar.

13 Por ser lo principal, a efectos de este trabajo, solo nos centraremos en la historia de la ley y en la doctrina nacional citada por él.

14 Considerando $18^{\circ}$ de la sentencia de primera instancia.

15 Considerando $19^{\circ}$ de la sentencia de primera instancia.
} 
comprometa u obligue a entregar dinero a otra y solo especialmente para aquellas operaciones en que la que recibe el dinero está obligada a restituirlo... Serán operaciones de crédito de dinero, como una especie de las que en general son obligaciones de dinero, todas aquellas, cualquiera sea el acto, contrato o combinación de actos y contratos, en las que una de las partes se obliga a entregar a la otra una cantidad determinada de dinero, y la otra a pagarla en un momento distinto de aquel en que se celebra la convención... Que considerando la amplitud de aquel concepto se excluyen expresamente aquellos contratos en que el dinero no se entrega con fines de crédito" 16 .

Luego, en cuanto a su análisis de la doctrina nacional, define las operaciones de crédito de dinero, siguiendo a Leslie Tomasello, como: "toda convención en virtud de la cual se da una prestación de presente contra una prestación de futuro" ${ }^{17}$; y señala que la operación objeto del juicio cae dentro de esta definición.

De esta manera, concluye que el Contrato encuentra su causa (motivo) en el Contrato Primitivo y que este no puede no ser una operación de crédito de dinero aunque aparezca tras un complejo de actos que individualmente considerados no lo sean.

Afirma que la calificación que corresponde a los actos señalados es la de un contrato de leasing que es: "un contrato de financiamiento, en virtud del cual, una persona solicita a otra, el préstamo de una suma de dinero y se obliga a restituirlo, en un plazo determinado, conforme a modalidades de pago singulares y quedando resguardados los derechos de quien presta, por una garantía máxima, como es la de consolidar -sin necesidad de ejercer acción judicial alguna- el dominio sobre un inmueble que se le ha transferido" ${ }^{18}$. Concluyendo que el leasing no pudo no considerarse como una obligación de crédito de dinero ${ }^{19}$.

Dicho lo anterior, Raúl Tavolari, ordenó rebajar los intereses al corriente de plaza y devolver lo pagado en exceso, pero no consideró que las contribuciones pudiesen considerarse como parte del interés.

\section{SENTENCIA}

Ambas partes dedujeron recursos de apelación contra la sentencia y en lo que a nosotros nos interesa, esto es si el leasing es o no una operación de crédito de dinero y por tanto se encuentra sujeta a la tasa máxima convencional en la fijación de los intereses, lo hizo Penta.

En su recurso Penta, apoyada por los informes en derecho elaborados por los profesores Raúl Varela Morgan y Juan Eduardo Palma Jara, sostuvo que si bien el leasing financiero es una forma de financiamiento, no es una operación de crédito de dinero y por lo tanto no queda sujeta a la tasa máxima convencional.

Apoyo esta tesis en los siguientes argumentos: a) así se desprende de la Historia de la Ley No 18.010, que tuvo como testigo privilegiado a Raúl Varela Morgan que en su informe avala esta tesis y muestra cómo durante el desarrollo del proceso legislativo el concepto

\footnotetext{
16 Considerando $20^{\circ}$ de la sentencia de primera instancia.

17 Considerando $17^{\circ}$ de la sentencia de primera instancia.

18 Considerando $29^{\circ}$ de la sentencia de primera instancia.

19 Considerando $29^{\circ}$ de la sentencia de primera instancia.
} 
PABLo P., Rodrigo “ "Interés máximo convencional en los contratos de leasing y otras figuras afines..."

de operación de crédito de dinero fue progresivamente reducido excluyendo, entre otras figuras, al leasing; b) el informe presentado por el profesor Palma sostiene que no todo financiamiento es una operación de crédito de dinero, y el leasing no lo sería por deferir su objeto de lo señalado en el artículo $1^{\circ}$ de la Ley $N^{o} 18.010$; c) el leasing es reconocido por la jurisprudencia judicial, la doctrina y una gran cantidad de resoluciones de la Administración del Estado, por lo que desconocer sus efectos propios equivale a introducir una fuerte incerteza en el mercado financiero; d) el leasing no puede ser asimilado al mutuo porque no paga impuesto de timbres y estampillas, y e) la SBIF no considera al leasing para fijar la tasa máxima convencional.

Por su parte, S.W. no agregó nuevos sustentos a su posición.

Con el mérito de las razones antes señaladas, los árbitros señalaron sobre el concepto de operación de crédito de dinero: "que el propósito de financiamiento no es un elemento por sí solo determinante de la definición legal de una operación de crédito de dinero. En efecto, la Ley 18.010 no alude a ese propósito en la definición, ni de manera positiva ni de manera negativa (como ocurriría si se excluyeran del concepto a aquellos actos que no tienen finalidad de crédito). De este modo, para que una operación de financiamiento encuadre dentro del concepto legal de operación de crédito de dinero antes citado, es necesario que la operación cumpla con los dos requisitos esenciales que conforman su definición, como son la entrega o promesa de entrega de dinero, por una parte, y la obligación restitutoria correlativa, por la otra" ${ }^{20}$.

Luego, y a propósito de lo anterior, sostienen que no forma convicción entre ellos el informe del profesor Varela, ya que "el concepto de operación de crédito de dinero no se refiere a ningún contrato en específico, sino como su mismo nombre lo indica se refiere a cualquier operación en que lo relevante es la entrega u obligación de entregar dinero con la obligación posterior de restituirlo" 21 .

Desde este punto, alcanzan la conclusión de que el concepto de operación de crédito de dinero no excluye la combinación de diversos actos y contratos conexos; opinión que sostienen en que:

1. El concepto de operación utilizado en el artículo $1^{\circ}$ de la Ley No 18.010 no es incompatible con un conjunto de actos, es más "debe entenderse que alude genéricamente a cualquier acto o conjunto de actos que lleven al resultado descrito por la ley. Así por ejemplo, el término operación es utilizado en el artículo $3^{\circ}$ números 10 y 11 del Código de Comercio y reiteradamente en la Ley de Mercado de Valores para referirse genéricamente a distintos actos que llevan a ciertos resultados específicos que el legislador ha pretendido regular".

2. "En el caso de las operaciones de crédito de dinero el hecho determinante para la calificación es la entrega u obligación de entrega de dinero, con la obligación de restituirlo en un momento posterior". Así lo confirmaría Ricardo Sandoval quien a propósito de este concepto señala: "al definir el concepto (de operación de crédito

\footnotetext{
20 Considerando $9^{\circ}$ de la sentencia de segunda instancia.

21 Considerando $12^{\circ}$ de la sentencia de segunda instancia.
} 
de dinero) el legislador emplea el término operación que no pertenece a la categoría jurídica sino a la ciencia económica. La operación supone uno o más actos jurídicos relacionados o vinculados entre sí para la obtención de una finalidad económica”.

3. "A la misma conclusión lleva la doctrina del objeto desarrollada por la doctrina civil moderna. El objeto de un contrato es esencialmente la operación que las partes pretenden realizar y que determina la naturaleza de la relación contractual... Por eso, una relación constituida por dos o más actos jurídicos conexos que se integran recíprocamente en su contenido, cooperando a un mismo resultado económico, debe ser considerada como un negocio unitario, sin que esa unidad se vea comprometida por el hecho de que las singulares declaraciones reunidas produzcan consecuencias jurídicas autónomas".

4. En la interpretación de la ley debe priorizarse el sentido literal de las palabras antes que otros criterios interpretativos entre los que se encuentra la historia de la ley (artículo 19 del Código Civil), a lo que se debe agregar que la Historia de la Ley No 18.010 no es lo suficientemente clara como para cumplir con los estándares del inciso segundo del artículo 19, así "una definición de operación de crédito de dinero que omita referencia a una combinación de actos no puede entenderse, en nuestra opinión, como una limitación a contratos de mutuo u otros que se materialicen solo en un acto jurídico. Esa particular intención del legislador, a diferencia de otras, no fue manifestada en la Historia de la Ley publicada y tampoco es armónica con el término operación que emplea la Ley 18.010, por lo señalado en las letras anteriores" 22 .

Concluyen que "para calificar una operación como de crédito de dinero son relevantes los elementos esenciales estipulados por la ley, esto es, la entrega actual o prometida de dinero y la obligación de restitución en una época posterior" 23 .

Una vez definido el concepto de operación de crédito de dinero. Los jueces se abocaron a calificar la operación en particular; así señalaron que ella es un leasing, que en el caso particular se compone por un arrendamiento y una promesa de compraventa.

Luego, sostuvieron que el leasing será una operación de crédito de dinero si "el resultado de dichos contratos es entregar dinero y generar la obligación de restituir posteriormente el dinero" ${ }^{24}$. Para sostener esta conclusión agregan que ella: "es coherente con lo señalado en sede administrativa por la Superintendencia de Valores y Seguros en su Oficio Ordinario No 1743 (Doc. No 4), donde se sostiene que 'respecto a la aplicación de la Ley 18.010 al contrato consultado [un leasing inmobiliario], es posible señalar que, dicha determinación por tratarse de un contrato atípico y sin regulación normativa precisa

\footnotetext{
22 Considerando $13^{\circ}$ de la sentencia de segunda instancia.

23 Considerando $14^{\circ}$ de la sentencia de segunda instancia.

${ }^{24}$ Considerando $17^{\circ}$ de la sentencia de segunda instancia.
} 
dependerá de cada caso, en atención a su naturaleza jurídica y su naturaleza específica, lo que debe resolver el tribunal previsto en el contrato'"25.

Así el tribunal arbitral de segunda instancia llega a la conclusión de que la relación contractual, calificada como leasing, que se genera por la interrelación entre el Contrato Primitivo y el Contrato, tiene la naturaleza de una operación de crédito de dinero y, por lo tanto, queda sujeta a la limitación de la tasa máxima convencional ${ }^{26}$.

Esto se acordó contra la opinión del señor Amunátegui quien estuvo por considerar el informe del profesor Varela y sentenciar que la intención del legislador fue excluir de la Ley No 18.010 las combinaciones de actos que dieran un resultado análogo a las operaciones de crédito de dinero ${ }^{27}$.

De este modo el tribunal consideró a este leasing como una operación de crédito de dinero y estimo que él debía encontrarse sujeto a la tasa máxima convencional ${ }^{28}$.

\section{COMENTARIO}

Todos los árbitros, salvo el señor Amunátegui, estuvieron por considerar que en este caso nos encontramos ante una operación de crédito de dinero y que por lo tanto la estipulación de intereses debe sujetarse a la regulación establecida en la Ley No 18.010 para esta clase de operaciones.

Los jueces señalaron que para reconocer esta clase de operaciones se debe centrar la atención en sus dos características esenciales: a) una parte entregue o prometa entregar dinero, y b) la otra parte deba devolverlo en un momento distinto.

Agregan que por el uso del término operación, que es más amplio que el de acto o contrato, la ley no ha limitado su regulación a convenciones que produzcan de manera directa las obligaciones señaladas en el párrafo anterior, sino que también regula toda combinación de actos que permitan alcanzar esos mismos fines.

Finalmente y con respecto al contrato de leasing considerado como tal, los jueces de segunda instancia estuvieron contestes en que él no siempre será una operación de crédito de dinero, sino que dependerá de cómo se estructure el negocio, habiendo de este modo algunos que son y otros que no son ${ }^{29}$.

Esta doctrina representa la solución que nos parece apropiada, y que es coincidente con la dada por Pedro Lira Urquieta para la antigua discusión sostenida, a principios del siglo XX, a propósito del límite de los intereses que establece el artículo 2.206 del Código

\footnotetext{
25 Considerando $18^{\circ}$ de la sentencia de segunda instancia.

26 Considerando $22^{\circ}$ de la sentencia de segunda instancia.

27 Disidencia de Miguel Luis Amunátegui M.

28 Sin perjuicio de lo señalado, los árbitros dieron en cuanto al objeto de la litis la razón a Penta, ello porque la relación contractual no comienza, según ellos, con el Contrato, sino con el Contrato Primitivo, y a la fecha del perfeccionamiento de este, la tasa máxima convencional superaba la tasa que se pactó.

Además de lo anterior, es importante poner al lector al tanto de que contra esta sentencia S.W. dedujo recursos de casación en la forma y en el fondo. Dichos recursos no llegaron a ser conocidos por la Corte Suprema por haber acaecido un avenimiento entre las partes.

29 Este mismo criterio puede encontrarse en el oficio ordinario No 1.743 de la SVS.
} 
Civil. En aquella época se debatía acerca de si este artículo era solo aplicable al mutuo, como lo sostenía Alfredo Barros Errázuriz, o si era aplicable a todos los actos en los que se estipulasen de cualquier manera intereses, como lo sostenía Lira Urquieta ${ }^{30}$.

A continuación, basados en esa doctrina y en un análisis general de nuestro ordenamiento; daremos algunos argumentos que reafirman la opinión de los jueces. Sosteniendo que no solo por el uso del elemento gramatical se alcanza la conclusión a la que ellos arribaron.

Esto nos parece necesario, ya que "el sentido de la ley" del que habla el artículo 19 del Código Civil, y que al ser "claro" impone al interprete la obligación de someterse al tenor literal de la norma, no parece ser suficientemente diáfano como para basar la resolución del caso solo en él; lo que nos obliga a explorar el espíritu de la legislación.

Sobre la interpretación de las leyes la doctrina más moderna conceptualiza las normas de interpretación de la ley, como normas de primer y de segundo nivel. Siendo las de primer nivel las que se usan para interpretar la ley, y las de segundo, aquellas que determinan el uso de las normas de primer nivel ${ }^{31}$.

En Chile la doctrina mayoritaria se inclina por sostener que en primer lugar debe aplicarse el criterio gramatical y no siendo este suficiente, debe recurrirse al histórico, al lógico y al sistemático, y de no ser ellos capaces de resolver el asunto, el intérprete debe echar mano al espíritu general de la legislación y a la equidad natural (esta es nuestra norma de segundo nivel).

Teniendo esto a la vista, a continuación daremos argumentos que reafirman la interpretación de los árbitros, recurriendo a la historia de la ley -en lo que no abundaremos mayormente por haberlo ya hecho el árbitro Tavolari-, y los sentidos lógicos y sistemáticos.

Ellos nos permitirán señalar que de seguirse la interpretación restrictiva que pretende excluir a las combinaciones de actos de las operaciones de crédito de dinero, se volvería un atentado contra diversas normas de orden público.

De este modo, procedemos a señalar:

1. En primer lugar que, a diferencia de lo sostenido por los árbitros de segunda instancia, pensamos que el elemento histórico nos obliga a considerar que el leasing podría quedar, según el caso, comprendido dentro de las operaciones de crédito de dinero; ya que el legislador desde los orígenes de nuestro derecho ha querido regular el pacto de intereses derivado de un financiamiento sea cual sea la forma en que se presente.

A su vez este ha sido el criterio en la legislación española -sumamente cercana a la nuestra-; cuya Ley de 23 de julio de 1908, de Represión de la Usura, que era conocida por el legislador chileno de 1980, en su artículo $9^{\circ}$ dispone: "lo dispuesto por esta ley se aplicará a toda operación sustancialmente equivalente a un préstamo de dinero, cualesquiera que sean la forma que revista el contrato y la garantía que para su cumplimiento se haya ofrecido" 32 .

\footnotetext{
30 Aguirre (1967) p. 19.

31 Bascuñán (2014) pp. 272-276.

32 Artículo $9^{\circ}$ de la Ley de 23 de julio de 1908, de Represión de la Usura o Ley Azcárate (España).
} 
Por otro lado, como lo señaló Tavolari, de la historia de la ley es absolutamente concluible el hecho de que el legislador quiso regular las operaciones de crédito de dinero, sin importar la forma que estas tomasen. Esta intención se manifiesta, además de en los pasajes citados por aquel árbitro, en el Mensaje dirigido por el Presidente de la República a la Junta de Gobierno; que indica, entre los motivos para modificar la legislación anterior: "Como el D.L. No 455 solo considera interés la suma que el acreedor puede cobrar por sobre el capital reajustado, acontece que un interés usurario al tiempo de celebrarse una operación de crédito de dinero puede convertirse en lícito por efectos de la variación posterior del IPC, lo cual resulta absurdo. Esta situación ha ocasionado incluso dudas en el público en cuanto a la existencia misma del delito de usura, lo que es de suyo inconveniente" 33 .

Manteniendo esta línea argumental, que sostiene que la intención permanente del legislador ha sido regular el pacto de intereses sea cual sea la forma en que se presenten para lo cual recurre a conceptos amplios que abarcan varios cursos de acción, vemos que las regulaciones anteriores manifestaban sin excepción la misma intención. El D.L. No 455 de 1974, la Ley No 4.694 de 1929, la Ley No 8.716 de 1947, y la Ley No 11.234 de 1953, buscaron regular los intereses en cualquier forma que apareciesen no limitándose al contrato de mutuo.

A este respecto, resulta particularmente claro lo dispuesto por la Ley No 11.234: "La misma limitación se aplicará a las demás operaciones de crédito que efectúen las empresas bancarias, sea por medio de avances en cuenta corriente, en virtud de contrato o simples sobregiros temporales, avances contra aceptación, pagarés, descuentos de otros instrumentos de crédito, o en cualquiera otra forma. Igualmente estarán sujetas al límite señalado en el inciso anterior las operaciones de crédito que puedan ejecutar las personas naturales o jurídicas" 34 .

Notamos así que el legislador siempre ha deseado determinar el interés usurario y reprimir la usura. Lo que no sería posible, como la larga historia de la humanidad lo demuestra, si no diese un concepto que abarcara todas las figuras tras las cuales este delito pueda presentarse. Así, sin haber ninguna prueba de que su intención durante el año 1980 haya sido modificar este criterio; debemos inclinarnos por la teoría que sostiene que el concepto de operación de crédito de dinero supera al de actos y contratos determinados y abarca a cualquier agrupación de actos que busquen y consigan que una parte entregue o se obligue a entregar dinero y otra se obligue a restituirlo en un tiempo distinto de aquel.

2. Como segundo argumento, digamos que la interpretación contraria atentaría contra el artículo 472 del Código Penal que tipifica el delito de usura y por lo mismo sería contraria a los artículos 22 y 24 del Código Civil.

El artículo 472 del Código Penal dispone: "El que suministrare valores, de cualquiera manera que sea, a un interés que exceda del máximo que la ley permita estipular, será castigado...”.

\footnotetext{
33 Mensaje del proyecto de ley que dio origen a la Ley No 18.010 de 1981.

34 Esta opinión tenía Pedro Lira U., citado por AGUIRRE (1967) p. 20.
} 
La usura es un delito que atenta contra el comercio y la economía ${ }^{35}$; contra el patrimonio y la voluntad del deudor ${ }^{36}$, y contra el orden público económico ${ }^{37}$.

El derecho teme las consecuencias nefastas que puede tener el cobro de intereses excesivos y por ello busca regular el pacto de intereses.

Los autores acuerdan que este tipo penal busca reprimir una conducta objetiva que es el suministro de valores con intereses que excedan los máximos que a ley permite estipular.

El legislador busca abarcar cualquier conducta que conduzca a esta finalidad, sin importar la forma bajo la cual se presente, lo que queda claro en el uso de la expresión: "de cualquier manera que sea".

Por esto ha dicho Garrido que no importa de la forma en que se haya actuado; el título no tiene trascendencia, puede ser un mutuo u otro acto -lo común es que sea otro acto- de origen civil o comercial ${ }^{38}$.

A este respecto, el uso de la expresión "valores" ha sido empleada por el legislador para cubrir todos los casos posibles y no solo el préstamo de dinero; lo que se quiere castigar es la usura económica y no la usura jurídica ${ }^{39}$.

Además por tratarse la usura de un tipo objetivo, el acuerdo del mutuante o de la parte que deberá pagar los intereses no elimina la ilicitud del negocio ${ }^{40}$, así cualquier acto que consiguiese estos fines sería nulo absolutamente por ser ilícito su objeto ${ }^{41}$.

Por ende una interpretación que intentase excluir de los alcances de la Ley No 18.010 a una operación que si bien no es un mutuo, consigue los mismos fines que este, atentaría contra el artículo 472 del Código Penal, vulnerándose los artículos 22 y 24 del Código Civil.

Por último, en otro orden de cosas, es importante tener presente que en el caso del delito de usura, con el fin de precaverse de las distintas formas que los usureros tienen para perpetrarlo; el antiguo Código de Procedimiento Penal contenía un sistema especial de prueba: "en la substanciación y fallo de los procesos instruidos para la investigación de estos delitos, los tribunales apreciarán la prueba en conciencia”.

35 Etcheberry (1997) p. 458.

36 Garrido (2002) p. 393.

37 Aguirre (1967) p. 11.

38 Garrido (2002) p. 394.

39 Etcheberry (1997) 459 p.

40 Etcheberry (1997) 458 pp. En esta consideración es que basa Aguirre su afirmación de que la usura es un tipo que atenta contra el orden público económico y no contra el patrimonio. Aguirre (1967) 11 pp.

41 Cabe hacer presente que así combatía la usura la doctrina española del siglo XIX por no estar ella regulada explícitamente en sus ordenamientos civil y penal. Al respecto señala Alcubilla: "La libertad que el vigente Código Civil sanciona en nuestra materia; si bien cabe señalar que se opone a un tipo de interés usurario lo establecido en su art. 1255 (al prohibir que las partes en los contratos que celebren incluyan cláusulas contrarias a las leyes, a la moral o al orden público), lejos de extinguirlas, ha multiplicado las argucias ideadas para asegurar al logrero sus ganancias y al necesitado su ruina: los pactos de retro, los juicios convenios, el abultamiento caprichoso del capitaly entregado a préstamo, el seguro sobre la vida constituido simultáneamente a favor del prestamista, la fijación de multas estupendas para el caso de mora y de indemnizaciones cuantiosas para el de reclamación judicial de la deuda... suelen transmitir a los usureros la totalidad de la hacienda del deudor, reduciéndolo a condición lastimosa de perpetua servidumbre, más cruel si cabe, que la que toleraba la Ley de las Doce Tablas". Citado por Vizcarro (1963) p. 22. 
Esto es indicativo de que siempre fue la intención del legislador permitir al juez determinar la existencia de la usura más allá de una determinada categoría de contratos; ya que se le da la posibilidad de ir siempre al fondo para determinar cuál fue la verdadera intención de las partes.

3. En tercer lugar, el no considerar a la operación de leasing de que trataba el Contrato Primitivo y el Contrato como una operación de crédito de dinero y someterla por tanto al régimen de la Ley No 18.010, sería contrario a los artículos 19 No 2 y 22 de la Constitución Política de la República (en adelante la "Constitución” o la "CPR”), y por ende contraía a los artículos 22 y 24 del Código Civil.

En efecto, no es correcto que dos operaciones que tengan exactamente los mismos resultados y en las que la intención de las partes sean exactamente las mismas sean tratadas de forma desigual; tanto por el legislador como por el intérprete, quienes irían contra el axioma que reza: "cuando existe la misma razón debe existir la misma disposición".

De hecho, la mayoría absoluta de la doctrina está conteste en que estas garantías constitucionales, se violan no solo al no ser respetadas por la Administración del Estado, sino también por el legislador -como lo indica el artículo 19 No 2- e, incluso, algunos agregan que ni siquiera el mismo poder constituyente puede ir contra ellas ${ }^{42}$.

El concepto de igualdad ante la ley se explica como el antónimo de "discriminación arbitraria". Así de él el Tribunal Constitucional ha dicho: "la igualdad ante la ley consiste en que las normas jurídicas deben ser iguales para todas las personas que se encuentren en las mismas circunstancias y que no deben concederse privilegios ni imponerse obligaciones a unos que no beneficien a otros que se hallen en condiciones similares. No se trata, por consiguiente, de una igualdad absoluta, sino que ha de aplicarse la ley a cada caso conforme a las diferencias constitutivas del mismo. La igualdad supone, por tanto, la distinción razonable entre quienes no se encuentran en la misma situación... La razonabilidad es el cartabón o standard de acuerdo al cual debe apreciarse la medida de la igualdad o la desigualdad" ${ }^{43}$.

Por su parte, similar definición ha dado la Corte Suprema: "por discriminación arbitraria ha de entenderse toda diferenciación o distinción realizada por el legislador o por cualquier autoridad pública que aparezca como contraria a la ética elemental o a un proceso normal de análisis intelectual; en otros términos, que no tengan justificación racional o razonable, lo que equivale a decir que el legislador no puede, por ejemplo, dictar una ley que imponga distintos requisitos u obligaciones a personas distintas en iguales circunstancias" $^{44}$.

Sobre la consideración de una norma y de su interpretación como discriminatorias. Fermandois señala que esto se da cuando imponga a personas que se encuentran realizando operaciones similares requisitos distintos ${ }^{45}$.

\footnotetext{
42 Fermandois (2006) p. 253.

43 Tribunal Constitucional, citado por Fermandois (2006) p. 254.

44 Corte Suprema, citada por Fermandois (2006) p. 255.

45 Fermandois (2006) p. 256.
} 
Visto lo anterior, podemos notar que dos operaciones que en sus fines son iguales no pueden ser tratadas de manera diferente por el legislador. Así el contrato de lease-back celebrado por Penta con S.W. que tiene los mismo fines y efectos que un mutuo; no puede ser tratado de una manera que vuelva las regulaciones legales, establecidas para proteger a los deudores y a la economía, inútiles.

Refuerza esta tesis el fallo del Tribunal Constitucional, en una sentencia que analizaba la razonabilidad de los intereses establecidos en el artículo 53 del Código Tributario ${ }^{46}$. En ella se ha dicho: "La garantía jurídica de la igualdad supone, entonces, la diferenciación razonable entre quienes no se encuentran en la misma condición; pues no se impide que la legislación contemple en forma distinta situaciones diferentes, siempre que la discriminación no sea arbitraria ni responda a un propósito de hostilidad contra determinada persona o grupo de personas, o importe indebido favor o privilegio personal o de grupo, debiendo quedar suficientemente claro que el legislador, en ejercicio de sus potestades, puede establecer regímenes especiales, diferenciados y desiguales, siempre que ello no revista el carácter arbitrario... De esta forma, un primer test para determinar si un enunciado normativo es o no arbitrario, consiste en analizar su fundamentación o razonabilidad y la circunstancia de que se aplique a todas las personas que se encuentran en la misma situación prevista por el legislador" ${ }^{37}$.

Luego continúa la sentencia: "no basta con que la justificación de las diferencias sea razonable sino que además debe ser objetiva. De este modo, si bien el legislador puede establecer criterios específicos para situaciones fácticas que requieren de un tratamiento diverso, ello siempre debe sustentarse en presupuestos razonables y objetivos que lo justifiquen, sin que, por tanto, queden completamente entregados los mismos al libre arbitrio del legislador" ${ }^{48}$.

Prosigue señalando: "que para poder determinar si infringe la igualdad ante la ley, es necesario atender a demás a la finalidad perseguida por el legislador para intervenir el derecho fundamental de que se trata, la que debe ser adecuada, necesaria y tolerable para el destinatario de la misma... para que la diferenciación resulte constitucionalmente lícita no basta que lo sea el fin que con ella se persigue, sino que es indispensable además que las consecuencias jurídicas que resultan de tal distorsión sean adecuadas y proporcionadas a dicho fin, de manera que la relación entre la medida adoptada, el resultado que produce y el fin pretendido por el legislador supere un juicio de proporcionalidad en sede constitucional, evitando resultados especialmente gravosos o desmedidos" ${ }^{39}$.

Concluye diciendo: "la igualdad ante la ley supone analizar si la diferenciación legislativa obedece a fines objetivos y constitucionalmente válidos. De este modo, resulta sustancial efectuar un examen de racionalidad de la distinción; a lo que debe agregarse la

\footnotetext{
46 Es de relevancia hacer presente que en este caso no se trata de una operación de crédito de dinero, sino que de una sanción por el incumplimiento de una obligación tributaria. Sin embargo, hemos escogido este fallo por ser claro en señalar que toda ley y su interpretación deben estar sujeta al principio de igualdad. Principio que de ser violado hace a la ley o a su interpretación inconstitucional.

47 Considerando $17^{\circ}$ STC, rol 1951-2011.

48 Considerando $18^{\circ}$ STC, rol 1951-2011.

49 Considerando $18^{\circ}$ STC, rol 1951-2011.
} 
sujeción a la proporcionalidad, teniendo en cuenta las situaciones fácticas, la finalidad de la ley y los derechos afectados" ${ }^{30}$.

Hecha la revisión anterior, debemos preguntarnos: ¿qué motivo podría tener el legislador para tratar a dos figuras que se usan con los mismos fines de una manera diferente? o ¿por qué un juez o intérprete, al analizar un caso como el que es objeto de este comentario, y advertir que lo querido por las partes no dista en nada de un contrato regulado por la ley, habría de aplicar una regulación distinta de la establecida para ese contrato, sobre todo cuando no hay ni siquiera una razón de texto legal que se lo mande?

Claramente en este caso, como lo determinaron los árbitros, el fin es financiar, entregar valores a S.W., el que debe ser devuelto en un tiempo distinto y posterior, y lo que en el contrato se denomina "renta" no puede ser otra cosa que el interés. Así, no hay motivo para regir este contrato, en lo que a los intereses se refiere, sino por las normas concernientes a las operaciones de crédito de dinero, lo otro sería una discriminación arbitraria en contra del deudor, que perdería una protección legal que por ser de orden público no le está permitido renunciar.

4. En cuarto lugar, digamos que Chile, en virtud del Pacto San José de Costa Rica, se encuentra obligado a combatir la usura, sea cual sea la forma y sea cual sea el contrato a través del cual ella se presente.

De este modo una interpretación que permitiera sustraer una operación de financiamiento de la regulación de los intereses que está permitido estipular atentaría contra las obligaciones internacionales de la República y por ende contra el los artículos 22 y 24 del Código Civil.

5. Como último argumento, debemos señalar que el legislador chileno siempre ha buscado regular el crédito, los intereses y demás operaciones semejantes, por ende la interpretación que busca excluir al leasing de las operaciones de crédito de dinero o restarlo de la regulación de los intereses atentaría, también por este motivo, contra el artículo 22 inciso segundo del Código Civil.

Algunos ejemplos de este deseo los encontramos en la regulación establecida para los réditos proveniente del crédito sea este de dinero (Ley No 18.010) o de especies (artículo 2.206 del Código Civil), y en los límites impuestos a los intereses cuando este consiste en una sanción civil, tributaria o de otro tipo (artículo 1.559 del Código Civil, artículo 53 del Código Tributario, artículo 19 del D.L 3.500 de 1980).

Pretender entonces que la legislación nacional excluye de los alcances de su intención a una operación determinada que sigue los mismos patrones y tiene los mismos efectos que las otras es absurdo y se opone a lo dispuesto en las normas de interpretación del Código Civil, especialmente en sus artículos 22 y 24.

50 Considerando $19^{\circ}$ STC, rol 1951-2011. 


\section{CONSIDERACIONES SOBRE OTRAS FIGURAS AFINES Y CONCLUSIONES}

Visto todo lo anterior y junto con celebrar las consideraciones de los árbitros, podemos afirmar que le legislador chileno, siguiendo la tradición clásica ${ }^{51}$, ha querido regular el mercado financiero y el monto de los intereses que está permitido estipular. Lo que ha hecho teniendo en vistas el evitar que sus normas sean dejadas sin efectos por alterar las partes la forma de los contratos, por la simulación o el fraude a la ley.

Siguiendo la opinión de los jueces, para determinar si nos encontramos ante una operación regulada por la Ley No 18.010 lo importante será reconocer si estamos ante una figura que busque el financiamiento por medio de una operación de crédito de dinero, lo que se deberá analizar en cada caso. Así por ejemplo no todo leasing es una operación de crédito de dinero; algunos son una compraventa, otros pueden ser un contrato aleatorio y otros un arriendo.

Lo mismo puede ocurrir en otras figuras como la compra de minerales por anticipado que a veces es un contrato aleatorio (lo natural es esto), o en los contratos de futuros, etcétera. Lo esencial es notar si el dinero se entregó con fines de crédito debiendo la contraparte devolver lo entregado en un tiempo distinto más un interés. Para ello, el mejor criterio es determinar que riesgos asume cada parte en el negocio que entre ellas ejecutan.

Así proponemos como criterio para el reconocimiento de las operaciones de crédito de dinero establecer: 1) si lo entregado es efectivamente dinero; 2) si este dinero debe devolverse a quien lo entrega en un tiempo distinto y determinado; 3) que el cálculo del dinero que debe devolverse este determinado o sea simplemente determinable, y 4) quien asume el riesgo del dinero. De estos, el primer criterio representa lo que es la entrega u obligación de entregar y los siguientes tres, la obligación de restituir en un tiempo distinto.

Así si una de las partes da dinero, la otra se obliga a devolverlo en un tiempo distinto de aquel en que se le entregó asumiendo ella los riesgos del dinero y siendo la suma a devolver determinada o simplemente determinable, entonces estamos ante una operación de crédito de dinero sujeta a la regulación de la Ley No 18.010.

De no ser esto así, lo más probable es que nos encontremos ante un financiamiento que no encierre una operación de crédito de dinero, sino otra clase de negocios jurídicos, como pueden ser el contrato de sociedad o algún contrato aleatorio.

Por ejemplo: la adquisición de acciones de una sociedad anónima es una forma de financiamiento que no queda comprendida dentro de la operación de crédito de dinero, ya que el financista se vuelve socio del desarrollador del negocio, asumiendo parte de los riesgos de la actividad. De esta manera no se cobran intereses, sino que lo que se hace es repartirse las utilidades y por ende no se aplica la regulación de la Ley No 18.010.

Para concluir, podría ser de utilidad aplicar el método señalado a una figura financiera que se usa cada vez más en el financiamiento de proyectos inmobiliarios. Denominada por la industria financiera: "Operación de Capital Preferente".

51 Vale la pena decir que esto no es patrimonio de occidente. El Corán prohíbe el cobro de intereses lo que ha llevado a los bancos de los países árabes a desarrollar sistemas de crédito en los cuales ellos comparten el riesgo de los deudores. Además hoy por hoy esta no es la norma en el oeste, donde la mayoría de los países contempla la libertad en el pacto de los intereses. 
PABLo P., Rodrigo — "Interés máximo convencional en los contratos de leasing y otras figuras afines..."

Ella consiste en la combinación de tres contratos que se firman de forma consecutiva: promesa de compraventa (o promesas de compraventa) en verde, opción de resciliación y opción de venta. Y se ejecuta entre dos partes: el financista y el financiado-desarrollador inmobiliario.

El proceder es que el financista y el financiado suscriben una promesa de compraventa por todas las unidades del proyecto a un precio, generalmente, más bajo de aquel que el desarrollador del proyecto pretende pactar con el público. Pagando en este acto el financista la suma que por ello corresponda.

Acto seguido se firma la opción de resciliación, por la cual el financiado-desarrollador inmobiliario adquiere el derecho a resciliar las promesas de compraventa que se han firmado con el financista. Ello porque el financiado buscará firmar nuevas promesas con el público, a un precio mayor, con lo que devolverá su dinero al financista y hará su ganancia. De esta manera a medida que vaya suscribiendo las promesas con el público irá resciliando el o los contratos firmados con el financistas.

Luego se firma la opción de venta, por la cual el financista adquiere el derecho de vender al financiado las unidades por las que se haya celebrado la promesa y que este no haya podido resciliar.

Este negocio, da al financista dos garantías para asegurar el pago del crédito: a) la propiedad sobre las unidades vendibles, y b) las garantías que por disposición del artículo 138 bis de la Ley General de Urbanismo y Construcciones se encuentra obligado a constituir el desarrollador inmobiliario que firme promesas de venta de proyectos que aún no cuenten con recepción definitiva, estas son: póliza de seguro o boleta bancaria de garantía, para el evento de que el contrato no se cumpla dentro del plazo o al cumplimiento de la condición establecidos por el promitente vendedor para su celebración.

En cuanto a la ganancia del financista esta consiste en un precio que se pacta por la opción de resciliación, el que generalmente se pacta en cuotas y que de pagarse estas anticipadamente recibe un premio al igual que el prepago de los créditos.

Para concluir la descripción, señalemos que la operación debe darse dentro de períodos de tiempo determinado, el que resulta de la combinación de la promesa y de la opción de resciliación.

Podemos ilustrar este negocio con el siguiente ejemplo: Inmobiliaria A, acude al Banco B, en busca de capital para desarrollar un proyecto que cuenta con 100 departamentos que pretende vender en 1.000 UF cada uno, y para el que requiere 50.000 UF.

Banco B acepta financiar y ambas empresas deciden llevar a cabo el capital preferente. Así Banco B, firma promesas de compraventa por cada una de las unidades del proyecto, pagando 500 UF por cada una. Luego se firma la opción de resciliación que tiene como precio la suma de 10.000 UF, que Inmobiliaria A se obliga a pagar en diez cuotas trimestrales de 1.000 UF cada una; pactándose un descuento si paga de forma anticipada. A su vez, firman la opción de venta que permite a Banco B vender todas las unidades que continúen en su poder Inmobiliaria A, a un precio de 1.000 UF por cada una si dos trimestres después de la cuota número diez, no ha resciliado aún todas las promesas y pagado el precio de la opción de resciliación. Además se establecen una serie de condiciones en las que Banco B puede utilizar su opción de venta. 
Visto lo anterior, viene la pregunta: ‘es esto una operación de crédito de dinero? Los actos jurídicos celebrados por separado no constituyen una operación de crédito de dinero, sin embargo la operación considerada como tal lleva a los mismos efectos que si se hubiese pactado un crédito con un interés (de un $8 \%$ anual en el caso del ejemplo).

Así, si aplicamos la jurisprudencia analizada a este caso y el razonamiento que en este comentario hemos llevado adelante, no podemos sino concluir que esta es una operación de crédito de dinero: se entrega dinero, debe devolverse tiempo después, la suma a devolver es determinable y el riesgo de la operación es soportado por el desarrollador inmobiliario.

Cosa distinta sería si no existiese la opción de venta, lo que convertiría al negocio en una compraventa con opción de resciliación, sin embargo, habría que ver las condiciones concretas del negocio.

\section{BIBLIOGRAFÍA CITADA}

Aguirre, Juan (1967): "El delito de usura: la comprobación de su cuerpo", Memoria de Prueba para optar al grado de licenciado en la Facultad de Ciencias Jurídicas, políticas y Sociales de la Universidad Católica de Chile.

Bascuñán, Antonio (2014): "El Mito de Domat", en: Atria, Fernando, Correa, Rodrigo López, Julián, Sierra, Lucas (editores): "Una Vida en la Universidad de Chile" (Santiago, Editorial la Ley) pp. 263-349.

De Estagiria, Aristóteles (2013): "Ética Nicomaquea y Política" (Traducción de Antonio López, Ciudad de México, Editorial Porrúa).

Etcheberry, Alfredo (1997): "Derecho Penal", Tomo III (Santiago, Editorial Jurídica de Chile, tercera edición).

Fermandois, Arturo (2006): “Derecho Constitucional Económico”, Tomo I (Santiago, Ediciones Universidad Católica de Chile, segunda edición).

Garrido, Mario (2002): "Derecho Penal”, Tomo IV (Santiago, Editorial Jurídica de Chile, segunda edición).

Labbé, Alberto (2010): “Guerra a los Intereses Excesivos”, Revista Chilena de Derecho, vol. 37 No 1: pp. 197-199.

Samuelson, Paul y Nodhaus, William (2010): "Economía” (Lima, Editorial Mc Graw Hill, decimoctava edición).

Ugarte, José Joaquín (2010): Curso de Filosofía del Derecho, Tomo I (Santiago, Ediciones Universidad Católica de Chile, primera edición).

VizCarro, Fernando (1963): El préstamo usurario (Barcelona, Colección Nero, primera edición).

Palma, Juan Eduardo (2014): Informe en derecho acompañado al juicio.

VARELA, Raúl (2014): Informe en derecho acompañado al juicio.

\section{Sitios Web CONSUltados}

Diccionario de la Real Academia de la Lengua Española, versión de internet, [fecha de consulta: 14 de abril de 2015]. Disponible en: www.rae.es. 


\section{NORMAS CITADAS}

Constitución Política de la República.

Convención Americana de Derechos Humanos, Pacto San José de Costa Rica.

Código Civil.

Código Penal.

Código de Procedimiento Penal.

Ley No 18.010 de 27 de junio de 1981, que establece normas para las operaciones de crédito y otras obligaciones de dinero que indica.

Decreto Ley No 455 de 25 de mayo de 1974, que fija disposiciones para las operaciones de crédito de dinero.

Ley No 4.694 de 27 de noviembre de 1929, que dispone que en los contratos mutuo de dinero o de depósito el interés no podrá exceder en más de una mitad al término medio del interés corriente bancario en el semestre anterior.

Ley No 8.716 de 4 de enero de 1947, que complementa el Código Penal y el Código de Procedimiento Penal en lo referente al delito de usura.

Ley No 11.234 de 9 de septiembre de 1953, que modifica, en la forma que señala, la ley general de bancos.

\section{HISTORIA LEGAL}

Historia de la Ley No 18.010 de 27 de junio de 1981, que establece normas para las operaciones de crédito y otras obligaciones de dinero que indica.

\section{LEGISLACIÓN COMPARADA}

Ley de 23 de junio de 1908 de represión de la usura o Ley Azcarate.

\section{Resoluciones Administrativas}

Oficio Ordinario No 1.743 de 2011 de la Superintendencia de Valores y Seguros.

Circular No 3.444 de 2008 de la Superintendencia de Bancos e Instituciones Financieras.

\section{JURISPRUDENCIA}

Illanes con Fisco (2012): Tribunal Constitucional 13 de septiembre de 2012 (recurso de inaplicabilidad constitucional artículo 53 del Código Tributario), rol 1951-2011, en la página web del Tribunal Constitucional [fecha de consulta: 14 de abril de 2015]. Disponible en: <http://www.tribunalconstitucional.cl/wp/expedientes? $\mathrm{rol}=1951-11 .>$ 